Brazilian Journal

of Chemical

Engineering

\title{
OPTIMIZATION OF PRESSURE-SWING DISTILLATION FOR ANHYDROUS ETHANOL PURIFICATION BY THE SIMULATED ANNEALING ALGORITHM
}

\author{
Rodrigo Battisti ${ }^{1 *}$, Carlos A. Claumann ${ }^{2}$, \\ Cintia Marangoni ${ }^{3}$ and Ricardo A. F. Machado ${ }^{2}$ \\ ${ }^{1}$ Instituto Federal de Educação, Ciência e Tecnologia de Santa Catarina, Criciúma, SC. Brasil. E-mail: rodrigo.battisti@ifsc.edu.br, \\ ORCID: 0000-0002-7763-4015 \\ ${ }^{2}$ Universidade Federal de Santa Catarina, Departamento de Engenharia Química, Florianópolis, SC. Brasil. ORCID: 0000-0003-2524-6501 \\ ${ }^{3}$ Universidade Federal de Santa Catarina, Departamento de Engenharia, Blumenau, SC. Brasil. ORCID: 0000-0003-1959-1456
}

(Submitted: March 31, 2018 ; Revised: June 28, 2018 ; Accepted: August 19, 2018)

\begin{abstract}
The present study addresses the novel application of the simulated annealing algorithm (SAA) to optimize the pressure-swing distillation (PSD) process for anhydrous ethanol purification. Three different softwares (Aspen Plus ${ }^{\circledR}$, Excel $^{\circledR}$ and Matlab ${ }^{\circledR}$ ) were integrated to simultaneously optimize seven design and operational variables. The configuration with the best TAC represented a $40.2 \%$ saving per year in comparison to the non-optimized PSD. Such reduction was achieved by using the higher acceptance probability and the slower temperature decrement. This saving is mainly related to operational cost reductions, a fact that evidences the viability of using the herein described optimization methodology to improve the PSD design. Keywords: Optimization; Simulated annealing; Pressure-swing distillation; Anhydrous ethanol.
\end{abstract}

\section{INTRODUCTION}

Great efforts have been made to find efficient and less environmentally harmful alternatives to oil-based fossil fuels. Ethanol is one of the most promising biofuels within the renewable energy group in production nowadays. In properly designed systems, ethanol has low carbon potential and is considered an excellent clean-alternative to gasoline (Kumar et al., 2010; Malhotra and Das, 2003) In the Brazilian market, light duty vehicles could be fueled with gasohol (18 up to $27.5 \% \mathrm{v} / \mathrm{v}$ of anhydrous ethanol in gasoline) and/or hydrous ethanol. However, to be mixed with gasoline, ethanol must be in anhydrous form, since the presence of water in the mixture can cause phase separation problems and engine damage (Belincanta et al., 2016). As a result, it is necessary to dehydrate the ethanol in the last step of its production process via a biological route, which is still the most widely used process. This, however, is not an easy separation technique due to the formation of a homogeneous minimum boiling point azeotrope formed between water and ethanol (Kiran and Jana, 2015)

The azeotropic phenomenon is present in a large number of chemical systems and occurs due to non-ideal behaviors. If chemical components are dissimilar and the repulsion forces are strong, the activity coefficients are higher than unity, leading to the formation of a minimum boiling point azeotrope, as in the ethanol-water mixture case. If chemical components are attractive, the activity coefficients are lower than unity and may lead to the formation of maximum boiling point azeotropes (Luyben, 2012). The ethanol-water system forms an azeotrope having

\footnotetext{
* Corresponding author: Rodrigo Battisti - E-mail: rodrigo.battisti@ifsc.edu.br
} 
a composition of $87.2 \% \mathrm{~mol}$ of ethanol at $1.0 \mathrm{~atm}$. Therefore, producing ethanol in the high-purity degree required for its use in engines is no longer possible by conventional distillation, since this composition is unaltered by partial boiling. In this case, the mixture behaves like a pure component with a fixed boiling point, producing vapor with the same concentration as the original liquid solution, eliminating the concentration gradient required for the mass transfer of the ethanol to the vapor phase (Balat et al., 2008; Kumar et al., 2010).

The separation of azeotropic mixtures is of great industrial interest and numerous special distillation processes have been developed and optimized, including extractive distillation (Kiss and Suszwalak, 2012; Luo et al., 2014; Muñoz et al., 2006; QuijadaMaldonado et al., 2014), azeotropic distillation (Kunnakorn et al., 2013; Luyben, 2008a; Pla-Franco et al., 2014), membrane distillation (Tsuyumoto et al., 1997) and pressure-swing distillation (PSD) (Li et al., 2015; Luo et al., 2014; Luyben, 2008b; Zhu et al., 2015). There are also studies showing the possibility of using a combination of different configurations to obtain an optimal flowsheet. Alcántara-Avila et al. (2012) demonstrated that a combination of a conventional column with external heat integration and an extractive column with ethylene glycol as entrainer showed better economic performance in obtaining anhydrous ethanol. Although extractive distillation presents relatively high energy costs, it is still the option of choice in the case of large-scale production of bioethanol fuel - being preferred over membrane distillation, pressure-swing distillation, azeotropic distillation, or hybrid methods combining these options (Kiss, 2013).

PSD has attracted special attention from researchers because it has the great advantage of not requiring any additional solvent to be introduced into the process. Due to this advantage, PSD is often mentioned as an alternative method to generally applied azeotropic or extractive distillation (Fulgueras et al., 2016). The concept of PSD is based on the fact that component mixing needs to exhibit sensitivity to pressure variation, which means that a simple increase or decrease in pressure can alter the relative volatilities of the components of the mixture with close boiling points or form an azeotrope (Kumar et al., 2010). In a typical chemical plant, distillation columns and their support facilities can account for approximately one third of the total capital cost and for more than half of the total energy consumption (Lladosa et al., 2011). Consequently, process design and optimization can have a significant impact on the overall process economy. Due to its operational complexity, the optimization of a distillation column can generate savings of $20 \%$ to $50 \%$ in the total energy consumption (Kiss et al., 2012)
Based on an objective function and considering the operational and economic constraints, engineers try to manipulate the design and the process variables in such a way that the optimal point is reached, that is, where the column presents the maximum performance with the lowest operational cost. From an economic point of view, the objective function to be minimized in a distillation process is usually the total annual cost (TAC). In order to obtain a minimum TAC, the PSD process can be optimized through several design and operational variables such as number of total trays $\left(\mathrm{N}_{\mathrm{T}}\right)$, feed tray location $\left(\mathrm{N}_{\mathrm{F}}\right)$, recycle tray location $\left(N_{R}\right)$, and reflux ratio $\left(R_{R}\right)$ (Liang et al., 2017).

The sequential iterative and the heuristic optimization are the methods most commonly adopted to optimize the PSD process described in the open literature. Li et al. (2015) optimized a PSD with partial heat integration to separate the maximum boiling point azeotrope ethylenediamine-water through the sequential iterative method. Wang et al. (2014) performed a rigorous steady-state simulation based on minimizing the total annual cost of the partial and total heat integration pressure-swing distillation processes implemented in Aspen Plus following the sequential iterative optimization method. Zhu et al. (2016) studied the separation of the ternary system acetonitrile/methanol/benzene via a triple column pressure-swing distillation (TCPSD). On the basis of minimum total annual cost, several operating parameters were optimized by the sequential iterative procedure. The authors were the first to optimize this complex process, and they demonstrated the most optimum column sequence to separate this ternary azeotropic system.

The heuristic optimization method was explored in two studies conducted by Luyben (2014 and 2013). One of these studies reported the azeotropic separation of the maximum boiling point azeotrope methanoltrimethoxysilane, whereas the other compared the extractive distillation to the pressure-swing distillation applied to separate the acetone-chloroform binary system, which forms a minimum boiling point azeotrope. One disadvantage of the interactive method lies in the fact that one variable is changed at each time to minimize the objective function. As the dimensionality of the design variables increases, the sequential approach imposes a heavy computational load, especially for coupled distillation processes with more than one column operating simultaneously. In this sense, numerical optimization algorithms become an attractive alternative to improve computational efficiency in the search for the global optimum in high complexity processes (Cheng et al., 2009).

Moreover, approaches based on deterministic optimization are somewhat limited if one takes into account the complexity of industrially relevant reaction/separation model systems, since the resulting 
performance will probably not be located in the global optimum domain. Given this shortfall, the alternative optimization approaches involving stochastic techniques have shown to be promising. They have been extensively studied in the literature for optimization of chemical and industrial processes involving highly non-linear functions. Non-derivative methods are preferred for solving non-convex problems such as the simulated annealing algorithm (SAA), genetic algorithm (GA) and particle swarm (PS) (Linke and Kokossis, 2003). Among these, SAA has the advantage of being relatively easy to code, even for complex problems, and being able to offer a good quality solution in an acceptable computing time. The SAA is based on the simulation of a thermodynamic system that begins with the selection of an initial random point at a high temperature and moves to a new neighborhood point that improves the objective function value. The differential characteristic of SAA lies in its ability to accept a point with a higher objective function value, which is based on a certain probabilistic measure that reduces the chances of converging to a local minimum (Šibalija and Majstorović, 2016). Several studies have proposed the application of this method to optimize industrial chemical processes, such as heat exchanger networks (Chaudhuri et al., 1997; Dolan et al., 1990 and 1989), process synthesis (Chaudhuri and Diwekar, 1997 and 1996), reactive distillation (Cardoso et al., 2000; Cheng et al., 2009), batch distillation (Hanke and $\mathrm{Li}, 2000$ ), azeotropic distillation (GutiérrezAntonio et al., 2014) and extractive distillation (García-Herreros et al., 2011). A recent study done by Wang et al., (2016) used the SAA method to design and optimize the PSD process in two case studies, for the methanol-chloroform and acetone-methanol systems. The authors showed the feasibility of applying the SAA method in the optimization of the PSD process, which deals with continuous and discrete variables simultaneously.

The most recent literature review related to pressure-swing distillation was performed by Liang et al., (2017). They found no published study involving the optimization of the PSD process using the waterethanol mixture. Encouraged by this, the aim of the present study was to apply the SAA technique to simultaneously optimize seven design and operation variables of the PSD process in order to obtain fuel grade anhydrous ethanol by taking into consideration the influence on the objective function to minimize the total annual cost. The solution was achieved through a communication routine set between the rigorous distillation process model implemented in Aspen Plus combined with the optimization technique in Matlab. Data transfer between software was done by Excel, with a programming interface in Visual Basic language (VBA). Different SAA convergence parameters were investigated in order to find the closest proximity to the global minimum optimum, until the most suitable parameters for this specific case were found.

\section{PROCESS DESIGN}

The first step in the purification process of the anhydrous ethanol produced by fermentation is often the recovery of the ethanol produced by microorganisms in the bioreactors through a distillation column, called "beer column", where most of the water content is retained with the solid part. The product output from this process, whose ethanol concentration is approximately $37-50 \%(\mathrm{w} / \mathrm{w})(19-28 \% \mathrm{~mol})$, is then concentrated in a rectification column until reaching the azeotropic concentration that generates hydrated ethanol. Finally, some additional process such as the azeotropic, extractive or pressure-swing distillation is required to produce anhydrous ethanol (Balat et al., 2008).

Mulia-Soto and Flores-Tlacuahuac (2011) performed a systematic comparison between several azeotropic separation techniques and they proposed a very attractive PSD process for ethanol dehydration. The product of the recovery process where the fermentation broth solids are removed and the ethanol is slightly concentrated, is considered as the feed stream for the PSD process. Thus, the same process conditions considered by Mulia-Soto and Flores-Tlacuahuac were adopted in the current study. These conditions worked as the base case for the optimization of the design and operational variables, which are of primary importance to the pressure-swing distillation process. The fresh feed stream consisted of $100 \mathrm{kmol} / \mathrm{h}$ of $20 \%$ mol ethanol at $90^{\circ} \mathrm{C}$, under atmospheric pressure. This temperature was selected because, according to the reference works, in industrial plants the fresh feed of the distillation column goes through a preheating in heat exchangers as a form of energy integration until reaching the temperature of $90^{\circ} \mathrm{C}$. Ethanol must be of high purity content and meet the criteria established in the legislation in order to be used in the transportation sector. Therefore, according to design requirements, the ethanol mole fraction in the product should be $\geq$ 0.995 (Kumar et al., 2010).

Figure 1 shows the typical PSD process flowsheet diagram indicating the streams and design conditions taken into account in the base case for this study. The PSD process consists of two columns, in which one column operates at a relatively higher pressure (HPC) and the other one operates at lower pressure (LPC). The pressure-swing has the purpose of bypassing the azeotropic point. For systems that form minimum boiling point azeotropes, as in the case of water-ethanol, the high-purity product stream is withdrawn from the bottom of one of the columns and the distillate stream 


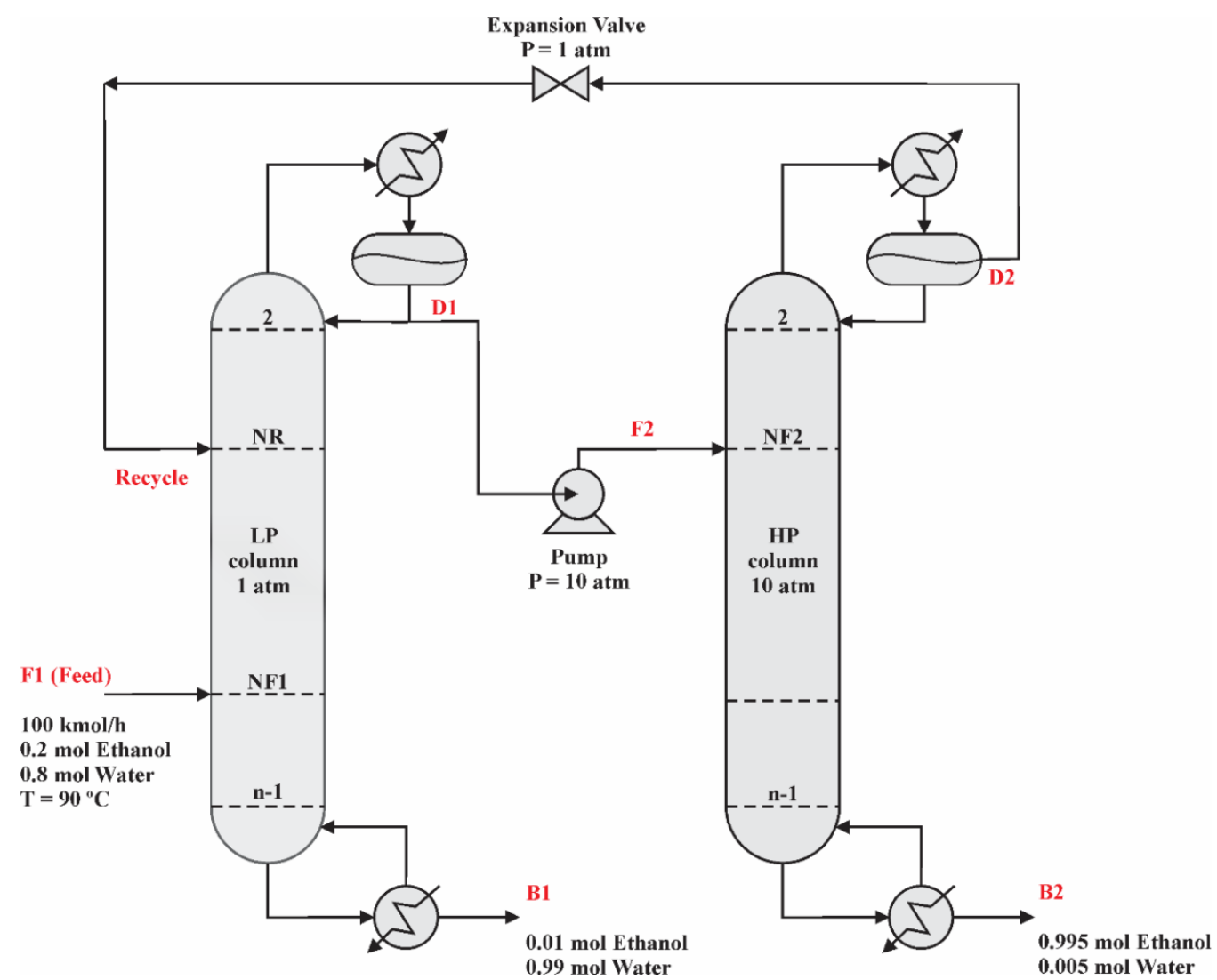

Figure 1. PSD process flowsheet diagram for anhydrous ethanol purification.

is recycled by passing through a valve that regulates the pressure (Luyben, 2013)

Although the ethanol-water azeotrope does not have high sensitivity to pressure change, several studies show that it is possible to carry out the dehydration using the pressure-swing distillation scheme (Kiran and Jana, 2015). As shown in Figure 2, the azeotropic composition of ethanol-water changes from $87.2 \% \mathrm{~mol}$ of ethanol at $1.0 \mathrm{~atm}$ to $79.4 \% \mathrm{~mol} \%$ of ethanol at $10 \mathrm{~atm}$ (the results shown in this figure were calculated using the thermodynamic model described in the Vapor-liquid equilibrium section). Thus, it is clear that this range of

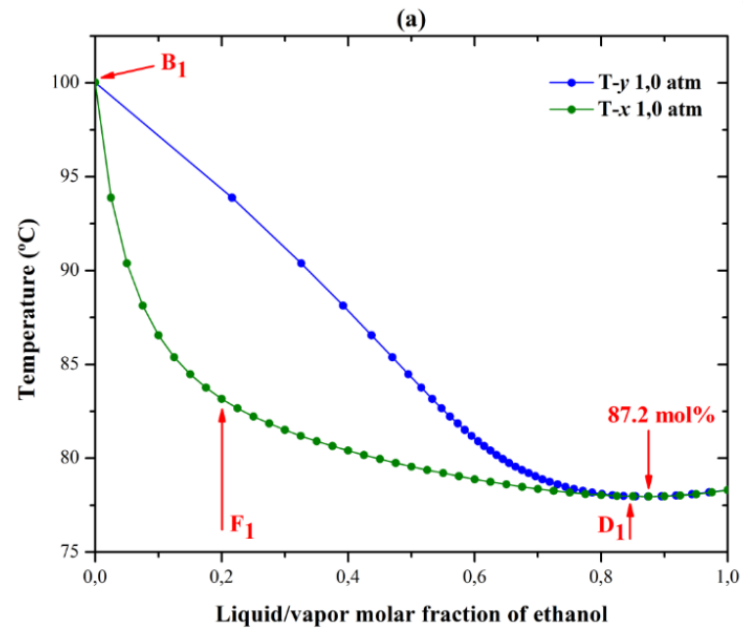

variation is large enough to bypass the azeotropic point, and high-purity degree ethanol can be produced.

\section{Vapor-liquid equilibrium (VLE)}

It is of primary relevance to accurately predict VLE data using an appropriate thermodynamic model in simulation software. According to Liang et al. (2017), the phase equilibrium constant $\mathrm{K}$ (for component $i$ and component $j$ ) determines the relative volatility $\left(\alpha_{i}\right)$ of a binary system. It is a critical property for design and optimization of the distillation process, defined by Equation (1).

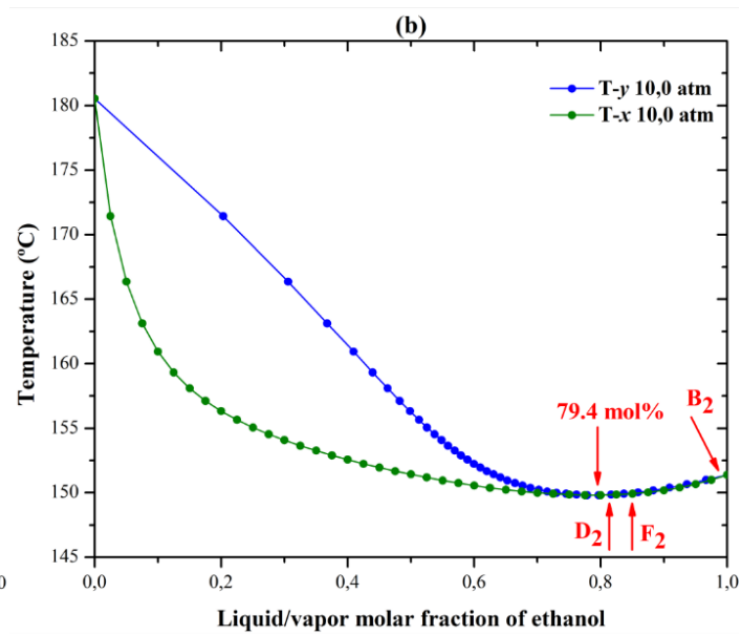

Figure 2. T-xy diagrams of the ethanol-water system. Azeotropes in (a) 1.0atm and in (b) 10atm. 
$\alpha_{i j}=\frac{K_{i}}{K_{j}}=\frac{y_{i} / x_{i}}{y_{j} / x_{j}}=\frac{f_{i}^{0 L} \gamma_{i}^{L} / P \varphi_{i}^{v}}{f_{j}^{0 L} \gamma_{j}^{L} / P \varphi_{j}^{v}}$

wherein $y$ is the vapor phase composition, $x$ is the liquid phase composition, $\mathrm{P}$ is the pressure, $\phi^{v}$ is the fugacity coefficient of the vapor phase, $f^{\circ L}$ is the liquid fugacity in the standard state, and $\gamma^{L}$ is the activity coefficient. The activity coefficient $\gamma^{L}$ characterizes the nonlinearity degree of the system; thus, precise simulated results are strongly dependent on the quality of the binary parameters of the liquid phase activity coefficient models (Lladosa et al., 2011). At the azeotropic point, the relative volatility $\left(\alpha_{i j}\right)$ reaches the unit value, which characterizes that physically the system cannot be further separated by conventional distillation.

Iqbal and Ahmad (2016) have tested several thermodynamic property models to predict the VLE data of the ethanol-water system. The authors have concluded that the WILSON-RK model is the most adequate to correctly predict the VLE data of the ethanol-water system, presenting a minimum error of $1.94 \%$ for the vapor phase composition and $0.33 \%$ for the phase temperature, so this model was chosen in this work. This thermodynamic package uses the Wilson activity coefficient model in the liquid phase and the Redlich-Kwong state equation in the vapor phase. Figure 3 shows the $x-y$ diagram for the ethanolwater binary system at pressures of 1.0 atm and 10 atm provided by the WILSON-RK model available in Aspen Plus. Such pressure variation produces a change in the azeotropic ethanol composition from $87.2 \% \mathrm{~mol}$ to $79.4 \% \mathrm{~mol}$, and it indicates the thermodynamic feasibility of using the pressure-swing distillation system within this specific range.

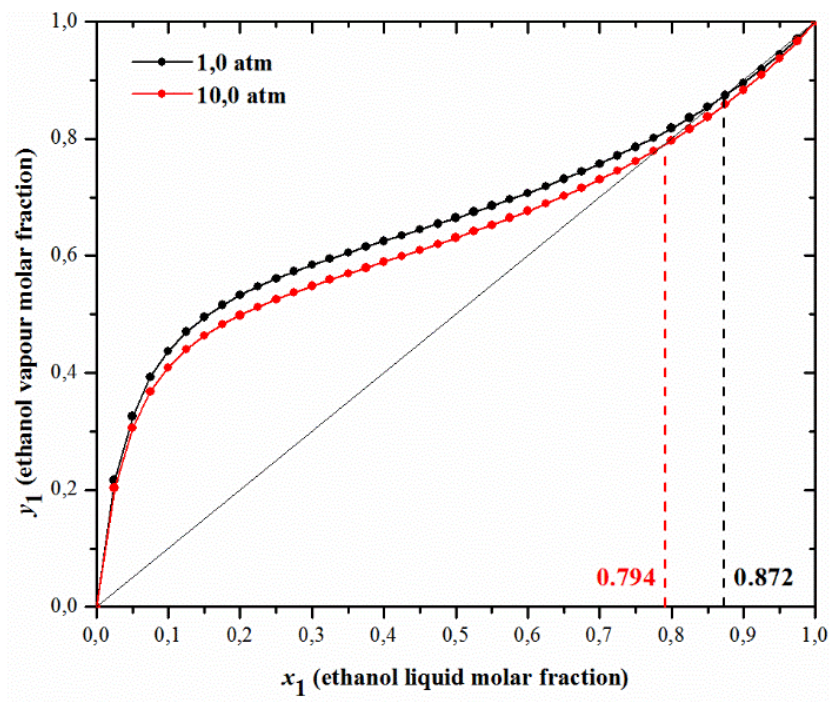

Figure 3. Binary $x-y$ diagram for ethanol-water system at pressures of $1.0 \mathrm{~atm}$ and $10 \mathrm{~atm}$ estimated by the WILSON-RK thermodynamic model.

\section{Steady state simulation}

The process flowsheet diagram shown in Figure 1 was implemented in Aspen Plus software using the RADFRAC block for rigorous distillation and the WILSON-RK thermodynamic package was used to predict the vapor-liquid equilibrium data. For a binary mixture having a pressure sensitive minimum boiling point azeotrope, the separation sequence is composed of two columns operating at different pressures (Muñoz et al., 2006). The feed $\left(\mathrm{F}_{1}\right)$ enters the LPC operating at atmospheric pressure and the distillate resulting from this column $\left(\mathrm{D}_{1}\right)$ presents ethanol composition approaching the minimum boiling point azeotrope $(\geq 0.85 \mathrm{~mol})$. This distillate is the feed stream $\left(\mathrm{F}_{2}\right)$ of the HPC operating at high pressure (10atm). The distillate from this column $\left(D_{2}\right)$ has a composition close to the azeotrope of the low-pressure column and is recycled to the LPC. The high-purity ethanol ( $\geq 0.995 \mathrm{~mol})$ is withdrawn in the bottom stream of the high-pressure column $\left(\mathrm{B}_{2}\right)$, which for economic viability needs to recover at least $98 \%$ of the ethanol that is fed into the process.

The ethanol purity specifications were $\geq 0.85 \mathrm{~mol}$ in the LPC, and $\geq 0.995 \mathrm{~mol}$ in the HPC. These targets were reached by using the "Design Spec/Vary" function in Aspen Plus by adjusting as the manipulated variable the distillate flow rate in the low-pressure column $\left(D_{1}\right)$ and the flow rate of the bottom product in the highpressure column $\left(\mathrm{B}_{2}\right)$. The degrees of freedom analysis in the steady state leads to the following hypotheses: (a) binary mixture; (b) total number of trays known; (c) the location of the feed streams and the recycle stream are known; (d) the operating pressures in each column are fixed and known. Once these conditions are met, the model convergence in the steady state is feasible.

The operating pressure in the LPC was set at 1.0 atm to enable using cool water (at $305.15 \mathrm{~K}$ ) in the condenser. The operating pressure of the HPC shall be designed to ensure at least a 5\% mol change, or more, in the azeotropic composition of the mixture (Seader and Henley, 1998). Therefore, the choice was made to operate the HPC at 10 atm in order to assure the minimum feasible margin for an operationally viable azeotropic concentration oscillation, as shown in Figure 3. The pressure swing from $1.0 \mathrm{~atm}$ to 10 atm was enough to bypass the azeotrope formation and to reach the desired purity, because the ethanol concentration in the LPC distillate was approximately $0.85 \mathrm{~mol}$ and the HPC distillate was close to $0.8 \mathrm{~mol}$. The number of stages is counted from the top and the reflux drum is considered the first stage, whereas the reboiler was set as the last stage in the column.

\section{OPTIMIZATION METHODOLOGY}

Once the steady state process was established, the selected variables were optimized in order to minimize 
the total annual cost (TAC). Therefore, seven variables were selected, namely: the number of low-pressure column trays $\left(\mathrm{N}_{\mathrm{T} 1}\right)$, the location of the low-pressure column feed tray $\left(\mathrm{N}_{\mathrm{F} 1}\right)$; the recycle tray location $\left(\mathrm{N}_{\mathrm{R}}\right)$; the reflux ratio of the low-pressure column $\left(\mathrm{RR}_{1}\right)$; the number of high-pressure column trays $\left(\mathrm{N}_{\mathrm{T} 2}\right)$; the location of the high-pressure column feed tray $\left(\mathrm{N}_{\mathrm{F} 2}\right)$; and the reflux ratio of the high-pressure column $\left(\mathrm{RR}_{2}\right)$. The optimization interval for these variables was set according to results of preliminary convergence tests conducted in Aspen Plus, aiming at generating physically compatible results. The optimization within the constraint range of the design variables was obtained using the Simulated Annealing Algorithm (SAA) available in Matlab, whose objective function based on the economic analysis was to minimize the TAC. The integration between the process modeled in Aspen Plus and the optimization algorithm in Matlab was done by a VBA code implemented in Excel to transfer data between software. Different SAA setting parameter configurations were studied to determine the particular conditions to find the closest results to the global optimum of the function within the reasonable convergence time of the algorithm.

\section{Economic analysis}

The PSD process is often optimized by minimizing the total annual cost (TAC), which is one of the indices most frequently used to measure the economic viability and profitability of a production process. The TAC is the objective function to be minimized by the SAA algorithm, and can be expressed as follows.

$\mathrm{TAC}(\$ /$ year $)=\frac{\text { annual capital cost }}{\text { payback period }}+$ annual operating cost

Capital cost $=$ collum vessel $\operatorname{cost}\left(\mathrm{C}_{1}\right)+$ plate $\operatorname{cost}\left(\mathrm{C}_{2}\right)$

+ heat exchangers $\cos t\left(\mathrm{C}_{3}\right)$

Operating cost $=$ annual steam $\operatorname{cost}\left(\mathrm{C}_{4}\right)$

+ annual cooling water $\operatorname{cost}\left(\mathrm{C}_{5}\right)$

The capital cost of the PSD process includes column vessels, trays and heat exchangers (reboilers and condensers). The design parameters and the sieve trays of the column were determined by the "Tray sizing" function available in Aspen Plus, considering the reflux vessel as the first stage and the reboiler as the last stage. The heat transfer coefficients of the reboiler and the condenser were $0.852 \mathrm{~kW} /\left(\mathrm{m}^{2} . \mathrm{K}\right)$ and $0.568 \mathrm{~kW} /\left(\mathrm{m}^{2} . \mathrm{K}\right)$, respectively (Luyben, 2006a). The operating time of the distillation system was set at $8000 \mathrm{~h} /$ year (Cao et al., 2016). A 3-year payback period was assumed and the M\&S index used was 1625.9 for the year of 2016, according to the CEPCI
(Chemical Engineering Plant Cost Index). Other additional costs such as pumps, valves and pipelines may be ignored for calculations because their costs are much lower than those described above and would not significantly impact the TAC (Zhu et al., 2015). The economic assessments and the sizing relations were provided by Douglas (1988) and may be written as follows.

(I) Column vessel cost (\$/year):

$\mathrm{C}_{1}=\frac{\mathrm{M} \& \mathrm{~S}}{280} \cdot 937.636 \cdot \mathrm{D}^{1.066} \cdot \mathrm{H}^{0.802} \cdot(2.18+\mathrm{Fc})$

wherein $\mathrm{Fc}=3.67 . \mathrm{Fp}, \mathrm{Fp}=1.00(\mathrm{LPC})$ and $\mathrm{Fp}=$ 1.15 (HPC). D is the column diameter (m) and $\mathrm{H}$ is the column height $(\mathrm{m})$ when $\mathrm{N}_{\mathrm{T}}$ is the number of total trays, which is expressed as:

$\mathrm{H}=0.61 \cdot\left(\frac{\mathrm{N}_{\mathrm{T}}}{0.75}-3\right)+6$

(II) Plate cost (\$/year):

$\mathrm{C}_{2}=\frac{\mathrm{M} \& \mathrm{~S}}{280} \cdot 97.243 \cdot \mathrm{D}^{1.55} \cdot \mathrm{H}^{0.802} \cdot \mathrm{H} \cdot 2.7$

(III) Heat exchangers cost (\$/year):

$\mathrm{C}_{3}=\frac{\mathrm{M} \& \mathrm{~S}}{280} \cdot 474.668 \cdot \mathrm{A}^{0.65} \cdot(2.29+\mathrm{Fc})$

wherein $\mathrm{Fc}=(\mathrm{Fd}+\mathrm{Fp}) \cdot 3.75, \mathrm{Fd}=1.35$ (kettle reboiler) and $\mathrm{Fd}=0.8$ (fixed tubesheet heat exchanger), $\mathrm{Fp}=0$ $(\mathrm{LPC})$ and $\mathrm{Fp}=0.52$ (HPC).

(IV) Annual steam cost (\$/year):

$\mathrm{C}_{4}=\frac{\mathrm{c}_{\mathrm{s}}}{453.515} \cdot\left(\frac{\mathrm{Q}_{\mathrm{R}}}{\lambda_{\mathrm{v}}}\right) \cdot 8000 \cdot 3600$

wherein $Q_{R}$ is the reboiler duty $(\mathrm{kW}), \lambda_{v}$ is the latent heat of vaporization $(\mathrm{kJ} / \mathrm{kg}) ; \mathrm{c}_{\mathrm{s}}$ is the steam price, being $7.72 \$ / G J$ for low-pressure steam $(433 \mathrm{~K}), 8.22$ \$/GJ for medium-pressure steam (457 K), and $9.88 \$$ / GJ for high-pressure steam (527 K) (Zhu et al., 2015).

(V) Annual cooling water (\$/year):

$$
\mathrm{C}_{5}=\mathrm{c}_{\mathrm{w}} \cdot\left(\frac{\mathrm{Q}_{\mathrm{C}}}{\Delta \mathrm{T}_{\mathrm{w}} \cdot \mathrm{c}_{\mathrm{p}} \cdot 1000}\right) \cdot 8000 \cdot 3600
$$

wherein $c_{w}$ is the cooling water price $(0.03 \$ / 1000 \mathrm{gal})$, $\Delta \mathrm{T}_{\mathrm{w}}$ is the temperature differential (design for $10^{\circ} \mathrm{C}$ ), and $c_{p}$ is the specific heat of water $(4.183 \mathrm{~kJ} / \mathrm{kg} . \mathrm{K})$. 


\section{Simulated Annealing Algorithm}

The simulated Annealing Algorithm(SAA) is a wellestablished optimization method and considered one of the techniques with greater variety of applications in problems coming from different research fields (Rangaiah, 2010). By analogy to thermodynamics, the concept of SAA is based on simulating the annealing phenomenon in solid materials. Kirkpatrick et al. (1983) were the pioneers to demonstrate that the statistical mechanics model used to simulate annealing processes, initially proposed by Metropolis et al. (1953), could be also adopted to solve optimization problems in general.

Physically, the annealing process is done by heating a solid, for example, to its melting point followed by gradual cooling, until its solidification is achieved again. In this process, slow cooling is essential to maintain a thermal equilibrium in which the atoms will find sufficient time to reorganize into a uniform crystalline structure with minimal energy. If the solid is cooled suddenly, its atoms will form an irregular and weak structure, with high energy, as a result of the internal effort expended. For each temperature level, considering that the temperature is reduced sufficiently slowly, it is assumed that the solid state reaches the thermal equilibrium, which is characterized by the Boltzmann distribution, Equation 11.

$P(E, T)=\exp \left(-\frac{E}{k_{b} T}\right)$

wherein $\mathrm{P}$ represents the probability, E represents the energy, $\mathrm{k}_{\mathrm{b}}$ is the Boltzmann constant and $\mathrm{T}$ is the temperature. The algorithm developed by Metropolis et al. (1953) calculates new energy values in each step and compares them with current energy values. If the new energy value found is lower, this new state is accepted. If the new energy value is greater than the current value, the state is not completely rejected, but is accepted on the basis of a probability having an inverse relationship with the energy difference (Rangaiah, 2010). The algorithm available in the Matlab optimization toolbox uses as the acceptance probability function for any temperature $\mathrm{T}$ the expression showed by Equation 12 .

$$
\mathrm{P}(\Delta \mathrm{E}, \mathrm{T})=\frac{1}{1+\exp \left(\frac{\Delta \mathrm{E}}{\max (\mathrm{T})}\right)}
$$

where $\Delta \mathrm{E}$ is the energy difference between the new and the old solution. Since both $\Delta \mathrm{E}$ and $\mathrm{T}$ are positive, the probability of accepting a new solution is between 0 and $1 / 2$ (MathWorks, 2016), thus the lower the temperature, the lower the acceptance probability. In addition, higher $\Delta \mathrm{E}$ leads to lower acceptance probability. This feature of the SAA of accepting points with higher energy based on a certain probabilistic measure reduces the chances of the method converging to a local minimum. In terms of process optimization with a set of design variables (d), the energy state (E) is equivalent to the objective function to be minimized. That is, E(d) will be reduced as the annealing begins. Initially a random vector of design variables $\left(\mathrm{d}_{\mathrm{i}}\right)$ will be chosen, the initial temperature of the system $\left(\mathrm{T}_{0}\right)$, the final temperature $\left(\mathrm{T}_{\mathrm{f}}\right)$, the criteria for thermodynamic equilibrium (maximum number of interactions for $\mathrm{T}$ ), and the cooling schedule $(\alpha)$. The SAA operation steps implemented in Matlab are shown in the flowchart presented in Figure 4.

SAA can be used to solve multivariable problems with continuous and/or discrete process parameters. Besides being easy to implement, it often provides an optimal overall solution to combinatorial nonlinear optimization problems, because SAA does not require gradient computation for its search-direction setting. The stochastic nature and guided probabilistic movements of the algorithm are two of its key aspects when it comes to the multimodal response function. It is worth determining the parameters affecting the algorithm convergence and the computational time

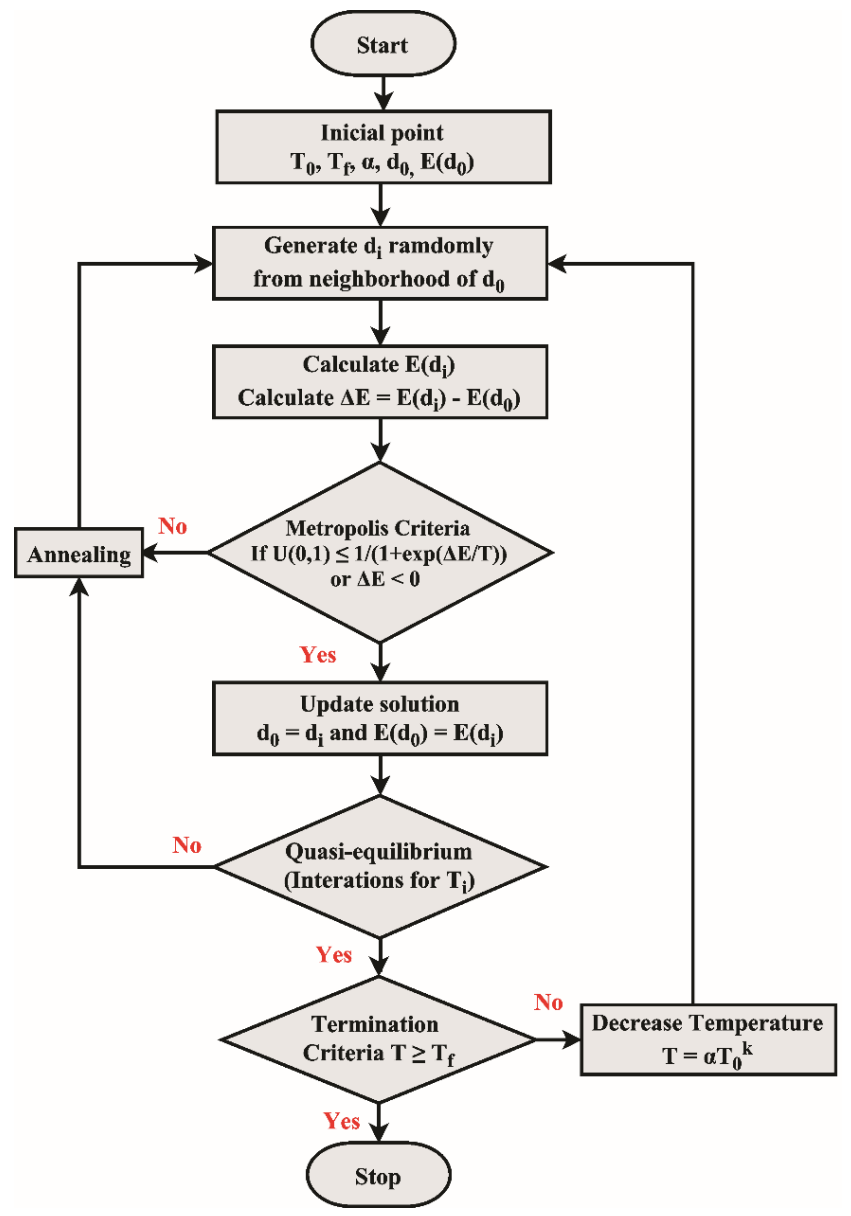

Figure 4. SAA operation flowchart. 
required (CPU time) in order to get its best performance (Šibalija and Majstorović, 2016).

\section{Generation of design variables}

First, the algorithm generates a set of random variables within the imposed constraint limits. Thus, according to the aforementioned, the PSD configuration used in the present study demands the optimization of seven variables, two continuous and five discrete ones. The optimization range to be used was established in preliminary tests that took into consideration the physical limitations of the separation and the satisfactory convergence of the process model implemented in the Aspen Plus simulator. The optimization range limits of the variables were determined as follows: number of total LPC trays $\left(25 \leq \mathrm{N}_{\mathrm{T} 1} \leq 50\right)$, LPC reflux ratio $\left(0.1 \leq \mathrm{RR}_{1} \leq 5\right)$, location of the LPC feed tray $\left(15 \leq \mathrm{N}_{\mathrm{F} 1} \leq 24\right)$, location of the LPC recycle tray $\left(10 \leq N_{R} \leq 14\right)$, total number of HPC trays $\left(25 \leq \mathrm{N}_{\mathrm{T} 2} \leq 50\right)$, HPC reflux ratio $(0.1$ $\left.\leq \mathrm{RR}_{2} \leq 5\right)$, location of the HPC feed tray $\left(10 \leq \mathrm{N}_{\mathrm{F} 2}\right.$ $\leq 20)$. The generation of a new point in the internal algorithm of Matlab for the next iteration is defined through the annealing function. The algorithm chooses the distance between the next test point and the current point through a probabilistic distribution with a scale that depends on the current temperature. The function used to generate the new iteration points was defined as the 'annealingfast' function (MathWorks, 2016), wherein the step length is equal to the current temperature, and the direction is uniformly random. The generation of the discrete variable values (number of trays, feed locations and recycle tray location) were truncated by a codification function set for the discrete values. This codification function rounds numbers to the nearest integer based on the value of the fractional part of the number, which have physical consistency to work as input in the flowsheet process developed in Aspen Plus.

\section{Initial temperature $\left(T_{0}\right)$}

The initial temperature is one of the most important SAA parameters, because it determines the probability of accepting, or not, an objective function solution worse than the previous one (Ben-Ameur, 2004). The temperature parameter $\mathrm{T}_{0}$ must be sufficiently large for the global optimum to be found; however, high initial temperatures result in long computational time. It is known that appropriate $\mathrm{T}_{0}$ values change from problem to problem, so the choice for the appropriate initial temperature value should essentially take into account the acceptance probability of the new solutions based on the Metropolis criterion. The acceptance ratio, which is the ratio of the accepted configuration numbers to the total number of new configurations, decreases as temperature decreases.
According to Equation 12, the acceptance probability function used in the algorithm lies between 0 and $1 / 2$. When the probability is close to 0 , the acceptance of a new point will be essentially deterministic, i.e., the probability of the algorithm to accept a solution presenting value higher than the previous one is practically zero. It can impoverish the search for the global optimum, because it would be subject to the easy conversion into a local minimum point. However, when the probability is close to $1 / 2$, the algorithm will possibly accept a solution of lower character, and it would enrich the chance to find the global optimum and to deviate from local minima. Another point to be considered is the computational effort, as higher initial temperatures will require longer convergence times, often making the optimization feature unfeasible.

By considering these principles, a methodology was adopted to obtain a suitable initial temperature for the proposed problem. Based on Equation 12, $\Delta \mathrm{E}$ was assumed to be equal to the standard deviation $\left(\Delta \mathrm{E}_{0}=\right.$ $\sigma$ ) of the converged solutions of the objective function (TAC), by considering the evaluation of 300 random points within the research range. Next, the initial temperature was considered to be the $\beta$ coefficient multiplied by the standard deviation of the obtained solutions, as shown in Equation 13. Finally, the $\beta$ coefficient could be obtained by substituting Equation 13 in Equation 12 and by isolating $\beta$, according to Equation 14. It was then proposed that it is possible to obtain an initial temperature for each desired acceptance probability $(\mathrm{P})$ of any desired between 0 and $1 / 2$.

$$
\begin{aligned}
& \mathrm{T}_{0}=\beta \cdot \Delta \mathrm{E}_{0} \\
& \beta=\frac{1}{\ln \left(\frac{1}{\mathrm{P}}-1\right)}
\end{aligned}
$$

In order to evaluate the influence of the acceptance probability $(\mathrm{P})$ on the global optimum solution result, in this study three acceptability probabilities $(\mathrm{P}=0.1$; $\mathrm{P}=0.25$ and $\mathrm{P}=0.4$ ) were evaluated, resulting in three initial temperatures $\left(\mathrm{T}_{0}\right)$, obtaining the approximate values of $250,000,500,000$ and $1,500,000$, respectively, as presented in Table 1. Although the variable is related to temperature, these values do not necessarily have physical significance, since the criterion that defines the dimension of the $\mathrm{T}_{0}$ parameter is directly related to the dimension of the variation of the objective function. In this case, as verified by the random evaluation performed, TAC is in the dimension range of $1 \times 10^{6}$, which leads to the explanation about the dimension of the initial temperature values in the range of $1 \times 10^{5}$. 


\section{Cooling schedule}

The cooling schedule is responsible for systematically reducing the temperature and internally storing the best point so far (Nourani and Andresen (1999). The annealing program is controlled by the parameter "Temperature Function" and it specifies the type of function that the algorithm uses to update the temperature. A slower temperature rate decrease is favorable to obtain the optimal global solution, but it extends the algorithm execution computational time. As the temperature decreases, the algorithm reduces the length of its search to converge into a minimum. For the present study, the exponential temperature function was used to reduce the temperature at each iteration, according to Equation 15.

$\mathrm{T}_{\mathrm{n}+1}=\mathrm{T}_{\mathrm{n}} \cdot \alpha^{\mathrm{k}}$

wherein $\alpha$ is the temperature decrement factor, generally within the range $0.8 \leq \alpha \leq 0.99$, and $\mathrm{n}$ is the temperature counter. The $\mathrm{k}$ is considered to be the annealing parameter, in this case, it is the same as the iteration number until reannealing. Reannealing raises the temperature in each dimension, depending on the sensitivity information. Then, the search is resumed with the new temperature value that is higher than the previous one. This feature allows the algorithm to avoid getting caught at a local minimum (Šibalija and Majstorović, 2016). Three temperature decrement factors $(\alpha)$ will be analyzed in order to verify its influence on the attainment of a satisfactory global optimal result in reasonable time, for variation purposes. After preliminary tests $\alpha=0.95, \alpha=0.97$ and $\alpha=0.99$ were selected as shown in Table 1 .

\section{Termination criterion}

The SAA termination criteria most generally used are: when the number of iterations exceeds the specified maximum number; when the best objective function value is lower than or equal to a specified tolerance; when the maximum execution time is reached; or when there is no change in the adjustment value of the objective function, i.e., the system "freezes" (Šibalija and Majstorović, 2016). The termination criterion used in the current study was based on the freezing temperature $\left(\mathrm{T}_{\mathrm{f}}\right)$, i.e., during the annealing process the temperature approaches a value of zero as the algorithm progresses, so that practically no worse configuration would be accepted according to the Metropolis criteria. It was observed that at the freezing temperature of 0.000001 , there are no changes in the objective function improving the optimization result, which is enough to obtain an optimal solution within a viable computation time. Therefore, the freezing temperature of 0.000001 was used to calculate how many objective function evaluations would be required for each subcase studied by the variation of SAA parameters. The results of the number of evaluations needed to achieve the "freezing" point were then set in the algorithm as a termination criterion.

\section{Matlab-Excel-Aspen Plus Interface}

The present optimization study was developed by an integration methodology between the Aspen Plus (version 7.1) simulator and the Matlab (R2015a) software, which was programmed through Visual Basic (VBA) language implemented in Microsoft Excel (2007), whose structure was presented by Claumann et al. (2015) The simultaneous use of these softwares brings benefits in face of exploring the best resources of each program. As an example, the Aspen Plus simulator has a great library of models for the implementation of processes from a graphical user-friendly interface. In terms of programming, the Matlab vector language represents an expressive time savings when one thinks of the amount of calculations that need to be performed in the optimization of a complex function. Matlab also has a collection of functions in the library (toolboxes), which are a set of functions already implemented in several areas of expertise, such as the optimization toolbox in which the SAA is inserted. Excel was only used for communication purposes in order to allow data transit between softwares.

The configuration of the optimization structure implemented in the current study is presented in Figure 5. The procedure that leads to the optimization of the process consists of the following steps: initially, a set of design variables is randomly generated in Matlab within the imposed constraints and then passed, through Excel, to Aspen Plus as design and operation variables. The steady state simulation is performed in Aspen Plus. After the convergence of the model is completed, the results of the variables necessary to calculate the objective function (TAC), such as the heat in the reboilers and condensers, temperatures and dimensions of the columns, are transferred back to Matlab, in which SAA is implemented. Thus, it can calculate the energy state of the current cost function and update the project variables according

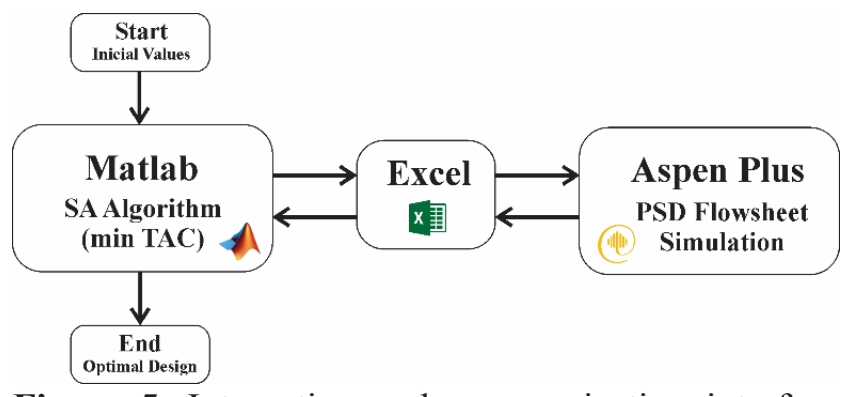

Figure 5. Integration and communication interface between software. 
to the algorithm parameters. The steps are repeated until the minimum energy state is reached. As a final result, we have the values of the seven optimal design variables that provide the minimum TAC. In order that the ongoing SAA optimization process was not affected, the non-converged solutions in Aspen Plus were discarded through a conditional statement in the Matlab algorithm, and the simulator was then restored to a standard condition after being fed with new inputs.

It is worth highlighting here a relevant difference of this work and the study made by Wang et al. (2016) They performed the optimization in Excel through VBA interface integration with Aspen Plus. In our study, the optimization is carried out in Matlab, which has the advantage of performing calculations faster, giving greater computational agility. Excel, as has been already said, is used only for communication between Aspen and Matlab. In addition, the process is the water-ethanol system, which had not been optimized by the SAA technique yet.

\section{RESULTS AND DISCUSSION}

The effective SAA performance is strongly dependent on the proper definition of the internal parameters of the algorithm. As was already mentioned, one of the most important SAA properties is its ability to "escape" from the local minimums. It is achieved by accepting some increasing movements in the cost function (Dolan et al., 1989). It can be established that the most important SAA parameters are the initial temperature $\left(\mathrm{T}_{0}\right)$, the final temperature $\left(\mathrm{T}_{\mathrm{f}}\right)$, the temperature decrement factor $(\alpha)$ and the number of interactions performed at each temperature. These factors directly affect the convergence of the algorithm and the required execution time (CPU time). Table 1 shows the different parameters tested herein and their influence on convergence and CPU times.

Regarding the acceptance probability, it is strongly dependent on the temperature. Thus, it is necessary to carefully calculate the initial temperature for the SAA to find good solutions (Ben-Ameur (2004). When the probabilistic effect tends to zero, the algorithm behaves only as a deterministic search, which ends up impoverishing the result, because it can be easily deceived and taken to a local minimum. However, the lower the acceptance probability, the lower the initial temperature and, consequently, the algorithm will present faster convergence, as observed in the CPU time values shown in Table 1 . When the acceptance probability tends to $1 / 2$, i.e., when the initial temperature is increased, the algorithm is able to initially accept a larger number of solutions with worse TAC, thus increasing the capacity to find a global optimal solution, but also increasing the execution time for convergence. It was observed that the increase in the initial temperature caused by the increase in the acceptance probability has the effect of increasing the quantity of the objective function evaluations, as the consequence of an increase in the execution time. However, this increase does not become an unfeasible factor for the optimization time. Regarding the cooling schedule, the exponential temperature function update was used, and three temperature decrement factors $(\alpha)$ were studied. It is clear that this factor has much greater influence on the execution time of the algorithm, thus leading to a significant increase in the number of objective function evaluations, as can be seen in Table 1.

As termination criterion, the final temperature $\left(T_{f}\right)$ was set to 0.000001 , since in all cases this was shown to be sufficient to reach the tolerance of $1.0 \times 10^{-}$ 4 in the evaluation of the error between the new and the old objective function. Under this level of tolerance, it can be affirmed that there is no significant improvement in the new value for the TAC, so it is enough to represent the optimal solution obtained for each case. It was observed that the calculated initial temperature $\left(\mathrm{T}_{0}\right)$ values were quite high, particularly in this case, due to the methodology used in this work, as previously described in the item Initial temperature $\left(T_{0}\right)$. According to Cheng et al. (2009) energy (E) and temperature (T) have the same unit because of the combination shown in Equation 11 for the Boltzmann distribution. In our case, since energy is represented by the TAC and its order of magnitude is near $1.0 \times 10^{6}$, we reached initial temperature values on the order of approximately 250,000 for $\mathrm{P}=0.1 ; 500,000$ for $\mathrm{P}=$ 0.2 ; and $1,500,000$ for $\mathrm{P}=0.4$.

Table 1. Parameters and time estimation for different configurations used in the SAA.

\begin{tabular}{ccccccc}
\hline $\mathbf{P}$ & $\boldsymbol{\beta}$ & $\boldsymbol{\alpha}$ & $\mathbf{T}_{\mathbf{0}}$ & $\mathbf{T}_{\mathbf{f}}$ & Number of evaluations $^{\mathbf{C P U}^{2}}$ & $\mathbf{T i m e}$ \\
\hline 0.1 & 0.455 & & 250,000 & 0.000001 & 510 & $0.32 \mathrm{~h}$ \\
0.25 & 0.910 & 0.95 & 500,000 & 0.000001 & 526 & $0.39 \mathrm{~h}$ \\
0.4 & 2.466 & & $1,500,000$ & 0.000001 & 547 & $0.43 \mathrm{~h}$ \\
0.1 & 0.455 & & 250,000 & 0.000001 & 862 & $0.59 \mathrm{~h}$ \\
0.25 & 0.910 & 0.97 & 500,000 & 0.000001 & 887 & $0.68 \mathrm{~h}$ \\
0.4 & 2.466 & & $1,500,000$ & 0.000001 & 921 & $0.75 \mathrm{~h}$ \\
0.1 & 0.455 & & 250,000 & 0.000001 & 2,612 & $1.58 \mathrm{~h}$ \\
0.25 & 0.910 & 0.99 & 500,000 & 0.000001 & 2,681 & $1.65 \mathrm{~h}$ \\
0.4 & 2.466 & & $1,500,000$ & 0.000001 & 2,785 & $1.83 \mathrm{~h}$ \\
\hline
\end{tabular}

${ }^{\mathrm{a}}$ Microprocessor: Intel ${ }^{\circledR}$ Core $^{\mathrm{TM}}$ i5-5200U CPU @ $2.20 \mathrm{GHz}$. 
Once the convergence parameters of the SAA algorithm were defined, the simulations were performed to optimize the TAC in the PSD system of the water-ethanol mixture. For each of the tested combination parameters, five runs were performed (quintuplicate simulations), which, in the end, totaled 45 runs for the determination of the minimum TAC. Table 2 presents the optimization results of all 45 runs performed through the different tested SAA parameters.

As can be observed, the minimum TAC value obtained was 1,910,238.3 \$/year, which resulted from the use of the slower temperature decrement factor $(\alpha=$ $0.99)$ and of the higher initial temperature $1,500,000(\mathrm{P}$ $=0.4$ ). The calculated deviation from the best obtained TAC shows that this TAC can be considered a good estimation of the optimal global solution since, for the quintuplicates, the obtained values were very similar. This configuration demonstrates that the slower and gradual lowering of the temperature improves the SAA performance in the search for the global optimum. The use of a higher initial temperature leads to a greater acceptability of bad solutions at the beginning, which gives the algorithm a chance to escape from local minima with greater aptitude.

When fixing the temperature decrement factor $\alpha=0.99$, for example, and by reducing the value of the acceptance probability from $\mathrm{P}=0.4$ to $\mathrm{P}=$ 0.1 , it was observed that the deviation between the optimal solutions reached $7.58 \%$. When the initial temperature is set to an acceptance probability $\mathrm{P}=0.1$, for example, and the temperature decrement factor $\alpha=$ 0.99 is reduced to $\alpha=0.95$, it can be observed that the discrepancy can reach $209.41 \%$, a fact that indicates that the factor $\alpha$ has a very significant influence on the attainment of the global optimal solution. The time required for execution in the case of the best obtained TAC solution was $1.83 \mathrm{~h}$, on average, which is a reasonably acceptable value when one works with multivariate and non-linear functions as in the case of this particular one.

If the specific SAA convergence parameters are not correctly designed for the case under study, it is easier for the algorithm to be trapped in a local minimum and to converge into a non-optimized global solution. For comparative visualization purposes, it was chosen to present the graphs of some configurations, as shown in Figure 6.

It was observed that all the configurations tended to an optimum point; however, the faster runs, i.e., those that reached the "freezing" temperature within a smaller number of objective function evaluations, are far from reaching the global optimum, which is represented by graphs (e) and (f). Initially, when the temperature is high, there is a great dispersion in the points, which is the consequence of the probabilistic characteristic of SAA. As the temperature is reduced, the dispersion is reduced and the TAC value tends to a minimum until the final temperature is reached. The graphs corroborate the results in Table 1, which shows the number of total evaluations for each case until the termination criterion is reached, approximately 510

Table 2. Optimization results of PSD using different convergence parameters for SAA.

\begin{tabular}{|c|c|c|c|c|c|c|c|}
\hline \multicolumn{8}{|c|}{$\alpha=0.95$} \\
\hline & \multirow{2}{*}{$\mathbf{P}$} & 0.1 & \multicolumn{2}{|r|}{0.25} & \multicolumn{3}{|c|}{0.4} \\
\hline & & TAC (\$/year) & Dev. ${ }^{a}$ & TAC (\$/year) & Dev. $^{a}$ & TAC (\$/year) & Dev. $^{\mathbf{a}}$ \\
\hline \multirow{5}{*}{$\underset{\Xi}{\Xi}$} & 1 & $1,930,883.6$ & $10.81 \%$ & $1,943,879.3$ & $17.61 \%$ & $1,962,323.2$ & $27.27 \%$ \\
\hline & 2 & $1,927,177.6$ & $8.87 \%$ & $1,932,546.2$ & $11.68 \%$ & $2,070,604.1$ & $83.95 \%$ \\
\hline & 3 & $2,000,916.0$ & $47.47 \%$ & $1,969,079.6$ & $30.80 \%$ & $1,942,502.1$ & $16.89 \%$ \\
\hline & 4 & $2,310,267.4$ & $209.41 \%$ & $2,038,502.9$ & $67.15 \%$ & $1,984,675.6$ & $38.97 \%$ \\
\hline & 5 & $2,032,283.8$ & $63.89 \%$ & $2,021,824.4$ & $58.41 \%$ & $1,942,483.6$ & $16.88 \%$ \\
\hline \multicolumn{8}{|c|}{$\alpha=0.97$} \\
\hline \multirow{7}{*}{$\stackrel{\mathscr{\Xi}}{\Xi}$} & \multirow{2}{*}{$\mathbf{P}$} & 0.1 & & 0.25 & & 0.4 & \\
\hline & & TAC (\$/year) & Dev. $^{\mathbf{a}}$ & TAC (\$/year) & Dev. $^{\mathrm{a}}$ & TAC (\$/year) & Dev. $^{\mathbf{a}}$ \\
\hline & 1 & $1,911,134.8$ & $0.47 \%$ & $1,925,995.1$ & $8.25 \%$ & $1,916,192.9$ & $3.12 \% 0$ \\
\hline & 2 & $1,928,823.9$ & $9.73 \%$ & $1,920,250.9$ & $5.24 \%$ & $1,917,135.6$ & $3.61 \%$ \\
\hline & 3 & $2,075,619.3$ & $86.58 \%$ & $1,920,222.3$ & $5.23 \%$ & $1,916,193.6$ & $3.12 \%$ \\
\hline & 4 & $1,915,251.7$ & $2.62 \%$ & $1,937,206.5$ & $14.12 \%$ & $1,916,192.6$ & $3.12 \%$ \\
\hline & 5 & $1,915,916.7$ & $2.97 \%$ & $1,920,222.1$ & $5.23 \%$ & $1,923,380.9$ & $6.88 \% 0$ \\
\hline \multicolumn{8}{|c|}{$\alpha=0.99$} \\
\hline & \multirow{2}{*}{$\mathbf{P}$} & 0.1 & & 0.25 & & 0.4 & \\
\hline & & TAC (\$/year) & Dev. $^{\mathrm{a}}$ & TAC (\$/year) & Dev. $^{\text {a }}$ & TAC (\$/year) & Dev. $^{\text {a }}$ \\
\hline \multirow{5}{*}{$\underset{\underline{\approx}}{\stackrel{n}{\Xi}}$} & 1 & $1,913,690.4$ & $1.81 \%$ & $1,913,352.8$ & $1.63 \%$ & $1,910,242.6$ & $0.00 \%$ \\
\hline & 2 & $1,914,901.6$ & $2.44 \%$ & $1,914,641.4$ & $2.31 \%$ & $1,910,238.3$ & $0.00 \%$ \\
\hline & 3 & $1,914,108.7$ & $2.03 \%$ & $1,913,351.0$ & $1.63 \%$ & $1,910,253.7$ & $0.01 \% 0$ \\
\hline & 4 & $1,924,727.2$ & $7.58 \%$ & $1,913,362.2$ & $1.64 \%$ & $1,910,239.9$ & $0.00 \%$ \\
\hline & 5 & $1,914,667.4$ & $2.32 \%$ & $1,913,395.9$ & $1.65 \%$ & $1,910,245.4$ & $0.00 \%$ \\
\hline
\end{tabular}

${ }^{a}$ Deviation calculated based on the best TAC obtained (best TAC $=1,910,238.3 \$$ year). 
(a)

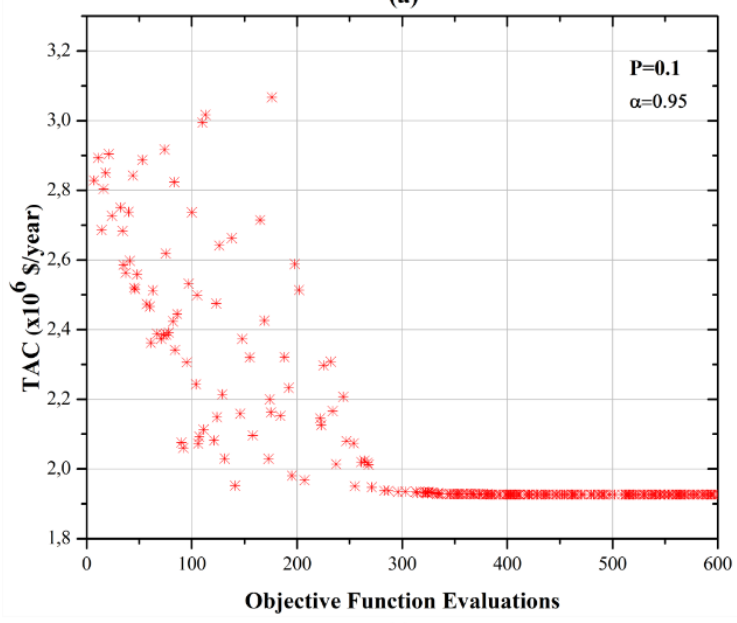

(c)

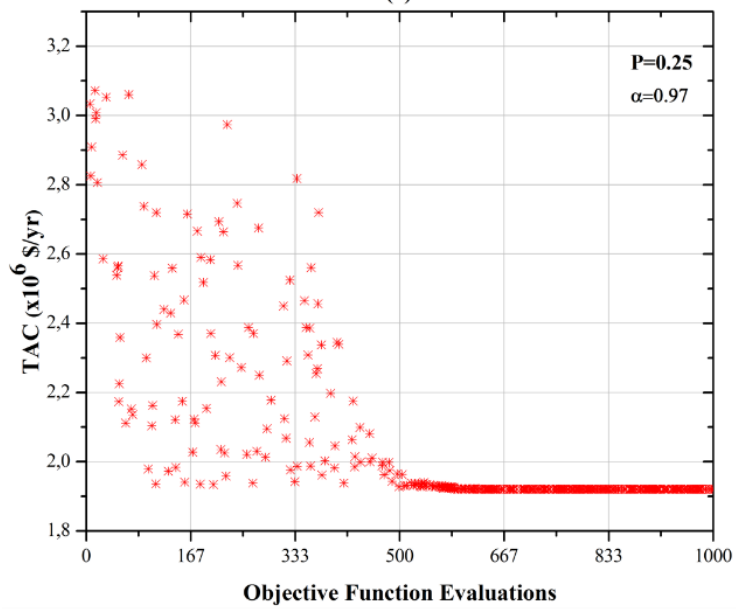

(e)

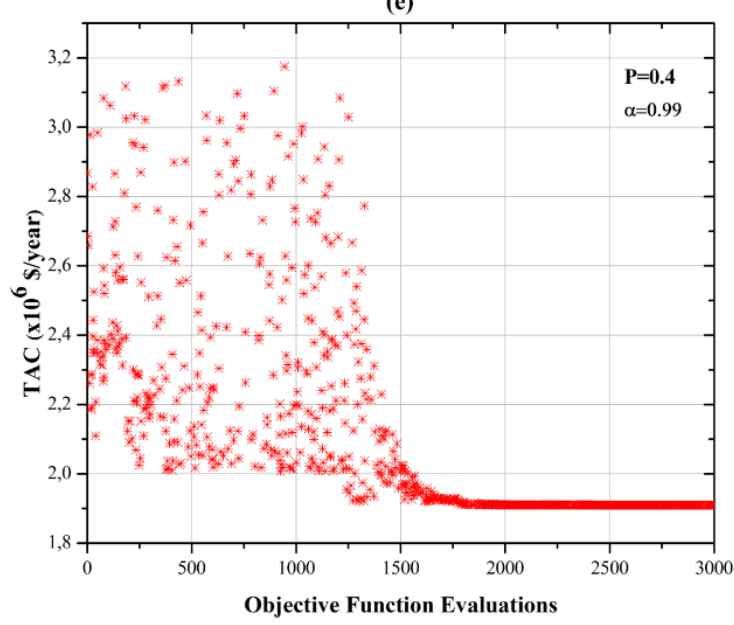

(b)

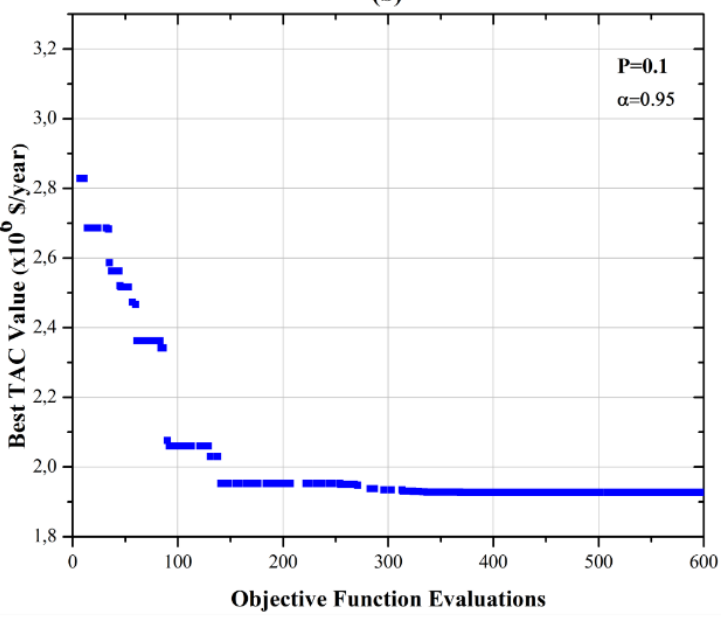

(d)

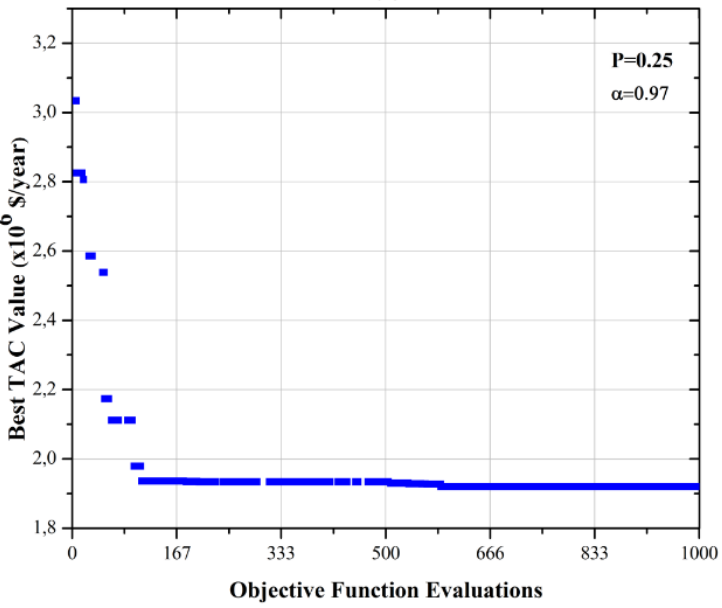

(f)

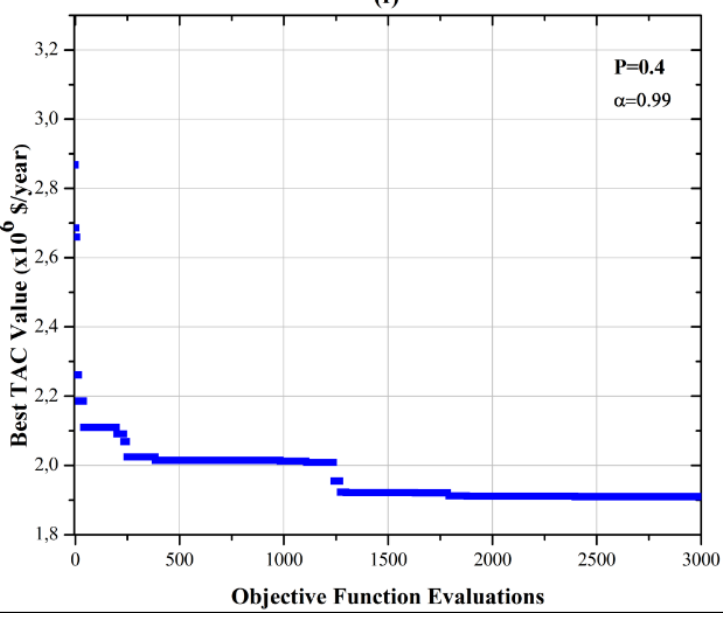

Figure 6. Optimization results for the ethanol-water system by the SAA: TAC values as the system is cooling (a) $\mathrm{P}$ $=0.1$ and $\alpha=0.95$; (c) $\mathrm{P}=0.25$ and $\alpha=0.97$; (e) $\mathrm{P}=0.4$ and $\alpha=0.99$; and the best TAC obtained as the system is cooling (b) $\mathrm{P}=0.1$ and $\alpha=0.95$; (d) $\mathrm{P}=0.25$ and $\alpha=0.97$; (f) $\mathrm{P}=0.4$ and $\alpha=0.99$.

for the first case $(\mathrm{P}=0.1$ and $\alpha=0.95), 887$ for the second case $(\mathrm{P}=0.25$ and $\alpha=0.97)$ and 2785 for the third case $(\mathrm{P}=0.4$ and $\alpha=0.99)$, on average.

The values of the design and operational variables for the optimal configuration that reached the best TAC are considered the optimum global minimum point and are presented in Table 3. The comparison between the PSD process studied by Mulia-Soto and Flores-Tlacuahuac (2011) and that of the present study demonstrated that it is possible to reach the same desired ethanol purity, while reducing energy consumption and the total annual cost. The study made by Mulia-Soto and Flores-Tlacuahuac (2011) did not calculate the TAC values. Therefore, for comparison 
Table 3. Comparison between the optimized and nonoptimized PSD processes.

\begin{tabular}{|c|c|c|}
\hline Items & $\begin{array}{c}\text { Non-optimized } \\
\text { PSD a } \\
\end{array}$ & $\begin{array}{c}\text { Optimized } \\
\text { PSD }\end{array}$ \\
\hline \multicolumn{3}{|l|}{ Low pressure column (LPC) } \\
\hline Feed flow rate $(\mathrm{kmol} / \mathrm{h})$ & 100 & 100 \\
\hline Feed composition (ethanol/water) & $0.2 / 0.8$ & $0.2 / 0.8$ \\
\hline Recycle feed rate $(\mathrm{kmol} / \mathrm{h})$ & 78.57 & 78.53 \\
\hline Top composition (ethanol/water) & $0.861 / 0.139$ & $0.851 / 0.149$ \\
\hline Bottom composition (ethanol/water) & $0.005 / 0.995$ & $0.005 / 0.995$ \\
\hline Bottoms rate $(\mathrm{kmol} / \mathrm{h})$ & 80.36 & 80.32 \\
\hline Distillate rate $(\mathrm{kmol} / \mathrm{h})$ & 98.21 & 98.21 \\
\hline er of trays & 28 & 37 \\
\hline Reflux ra & 4.725 & 2.126 \\
\hline & & 23 \\
\hline & & 13 \\
\hline & 0 & 0.3 \\
\hline Conder & 375 & 3456.1 \\
\hline Reboiler duty (kW) & 332 & 2785.2 \\
\hline \multicolumn{3}{|l|}{ High pressure column (HPC) } \\
\hline eed flow rate $(\mathrm{kmol} / \mathrm{h})$ & 98.21 & 98.21 \\
\hline & $0.861 /$ & $0.851 / 0.14$ \\
\hline & $27 /$ & $0.815 / 0.185$ \\
\hline ethanol/water) & $0.997 / 0.003$ & $0.996 / 0.004$ \\
\hline B & 19. & 19.68 \\
\hline & 79. & 78.53 \\
\hline er of trays $\left(\mathrm{N}_{T 2}\right)^{b}$ & 28 & 40 \\
\hline Reflux ratio $\left(\mathrm{RR}_{2}\right)$ & 0.435 & 1.669 \\
\hline Feed stage ( $\left.\mathrm{NF}_{\mathrm{F} 2}\right)$ & 14 & 13 \\
\hline Stage pressure drop $(\mathrm{kPa})$ & 0.3 & 0.3 \\
\hline & & 1949.6 \\
\hline & & 2236.0 \\
\hline Total ope & & $1,406,112.6$ \\
\hline & & $1,512,377.2$ \\
\hline $\mathrm{TAC}^{\mathrm{c}}(\$ /$ year $)$ & $3,197,625.3^{\mathrm{d}}$ & $1,910,238.3$ \\
\hline
\end{tabular}

${ }^{a}$ Mulia-Soto and Flores-Tlacuahuac (2011).

${ }^{\mathrm{b}}$ Excluding the reboiler and condenser.

c 3-year payback period.

${ }^{\mathrm{d}}$ Calculated by the methodology described in the item Economic analysis.

purposes, the values were calculated through the methodology described in the item Economic analysis. It is evident, based on Table 3, that the purification system by the optimized PSD assures the production of an ethanol with purity higher than $99.5 \% \mathrm{~mol}$, which is the recommended limit for its use in the transportation sector. In addition, from the bottom of the LPC, a water-rich stream is produced, i.e., less than 0.0048 molar ethanol is lost, thus showing that, under these conditions, $98.41 \% \mathrm{~mol}$ of all the fed ethanol is recovered. Thus, it indicates that there is a successful and efficient separation of both components of the mixture and recovery viability.

According to Hosgor et al. (2014), the increase in the reflux ratio improves the purity of the distillate, but also increases the heat load at the bottom. Therefore, under the precondition of assuring the distillate purity and minimizing the heat load in the reboiler, there is an optimal reflux ratio, which minimizes the TAC, as is also the case of other design parameters. By comparing the design variables of the optimized PSD to the nonoptimized PSD studied by Mulia-Soto and FloresTlacuahuac (2011), the reflux ratio that minimized the
TAC decayed from 4.725 to 2.126 in the LPC. The reduction in the reflux ratio in the LPC leads to reduction in the heat load of the reboiler, which, consequently, is related to the reduction in the total annual operating cost. But, when the HPC was observed, the reflux ratio increased from 0.435 to 1.669 . Even with this increase, there was a reduction in the heat load of the reboiler in this column. This fact is related to the other design variables that were optimized, mainly to the total number of trays. The optimized HPC presented a 12tray increase in comparison to the non-optimized PSD, which means that the stripping section is less required in the process since a larger number of trays leads to higher rectification. Thus, this increase in the number of trays would compensate the heat load in the reboiler to obtain the same purity as the required one.

The calculated TAC, for the non-optimized PSD system, was $\$ 3,197,625.3$ per year, whereas the TAC obtained by the optimized configuration was \$ 1,910,238.3 per year, which would represent a significant saving of $40.2 \%$ per year. The major difference in cost was observed through the reduction in operating cost, which decayed from $\$ 2,536,443.7$ per year in the non-optimized PSD to $\$ 1,406,112.6$ per year in the optimized PSD. This operating cost is mainly related to the energy expended in the reboilers and condensers. It indicates that, even if a column with more trays is required, its rectification is improved and its cost-effectiveness is offset by the reduction in the energy demand along peripherals that operate at lower loads and, consequently, reduce energy consumption. The feed and recycle streams had no great influence in terms of TAC minimization within the imposed constrains, since the feeding and recycling stages were practically unchanged in the comparison between optimized and non-optimized systems.

The liquid and vapor phase composition profiles for the SAA-optimized distillation columns that exhibited the global minimum TAC are shown in Figure 7 (a) and (b). The temperature profiles along the column stages are shown in Figure 7 (c) and (d) for the LPC and HPC, respectively. Large temperature variation from tray to tray indicates the region where the compositions (water or ethanol) are changing significantly (Luyben, 2006b). There is a noticeable increase in temperature near the bottom of the LPC as the water is being concentrated near $100^{\circ} \mathrm{C}$. In stage 23 , a temperature peak is also observed, which is due to the fresh feed stream that is entering in a superheated state, a fact that increases the vapor flow rate in the rectification section. In the HPC, the minimum boiling point azeotrope is withdrawn at the top of the column, as the purified anhydrous ethanol has higher temperature than the azeotropic mixture and exits at the bottom of the column. This temperature increase in the HPC stripping section is also evident, as there 

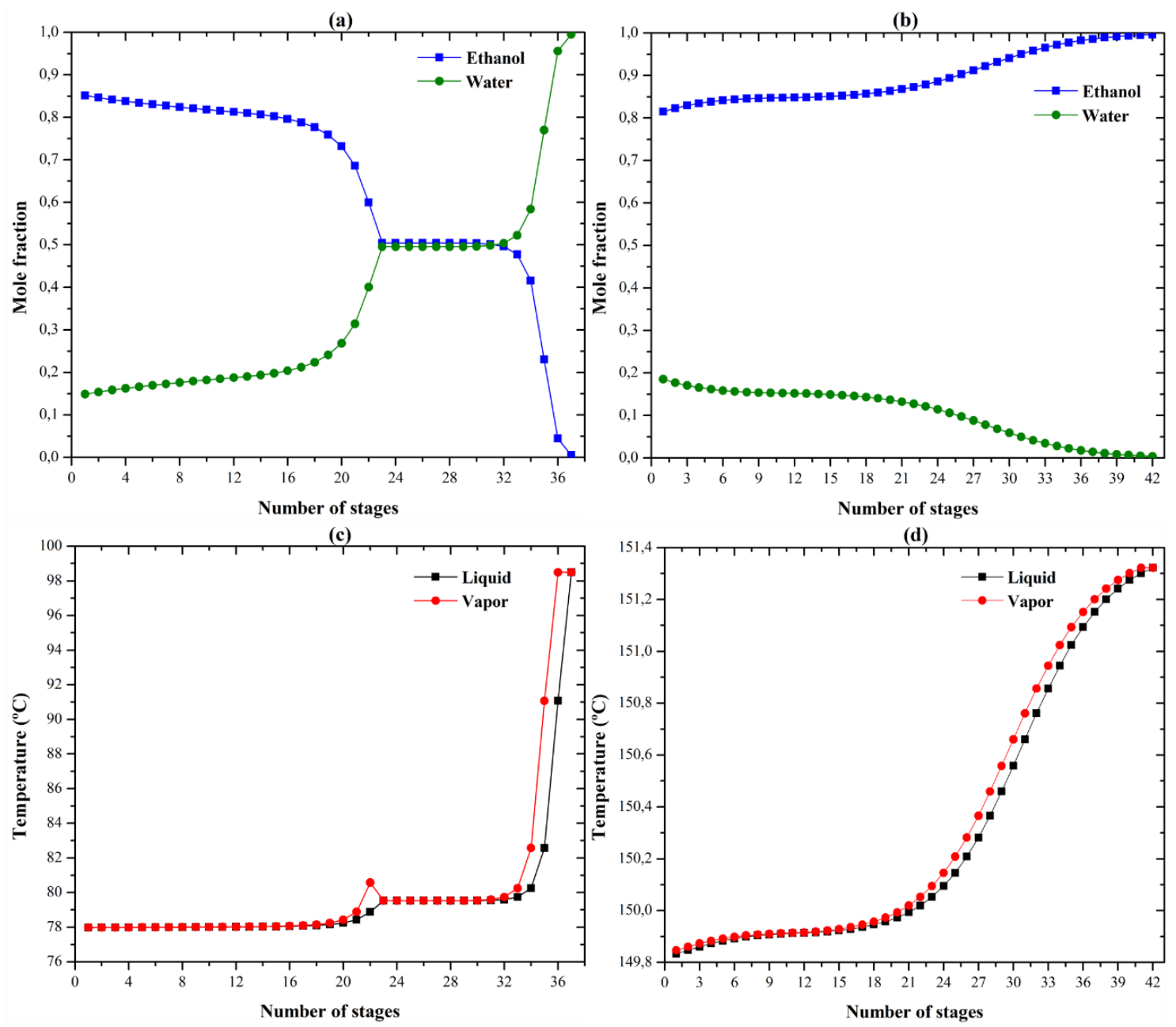

Figure 7. Composition profile in each stage for the ethanol-water system in the optimal configuration in (a) LPC and (b) HPC; Temperature profile in each stage along the columns (c) LPC and (d) HPC.

is the tendency to purify the anhydrous ethanol at the bottom of the column.

Accordingly, it can be observed that the separation of the azeotrope happened as expected and that the optimization method allowed gains without detriment to the separation efficiency. The optimized PSD design revealed potential savings in terms of total annual cost when it was compared to the non-optimized process, thus proving the feasibility of the unpublished optimization methodology for this specific process, whose objective was to make the process more economically competitive for the industrial sector.

\section{CONCLUSION}

The main contribution of the current study is the application of the SAA optimization method in the anhydrous ethanol purification process by the PSD process. The major emphasis was the use of three different softwares, which were integrated by a programming methodology through VBA language for their application in the optimization solution of the design variables. It was possible to obtain the configuration that minimized the TAC of the process through this methodology. The results made it clear that the use of SAA, although it cannot assure a globally optimized design in all runs, was shown to have advantages as a good probability of obtaining the global optimum in a reasonable algorithm execution time.

The optimized design of the pressure-swing distillation for anhydrous ethanol purification through the use of SAA had not been explored in the literature and presents itself as an unprecedented application for this process. The obtained design variables mainly minimized energy costs, and represented an expressive savings of approximately $40.2 \%$ per year in comparison to the non-optimized PSD used as comparison in the literature. It reinforces the feasibility of applying the SAA optimization method to obtain optimized engineering design in complex processes such as the pressure-swing distillation.

\section{ACKNOWLEDGMENTS}

The authors gratefully thank CAPES (Coordination for Improvement of Higher Education Personnel) for 
the financial support and UFSC (Federal University of Santa Catarina) for the technological support granted.

\section{REFERENCES}

Alcántara-Avila, J.R., Kano, M., and Hasebe, S., Environmental and economic optimization of distillation structures to produce anhydrous ethanol, in: Computer Aided Chemical Engineering, 30, 712-716 (2012). https://doi.org/10.1016/B978-0444-59520-1.50001-4

Balat, M., Balat, H., and Öz, C., Progress in bioethanol processing. Progress in Energy and Combustion Science, 34, 551-573 (2008). https://doi. org/10.1016/j.pecs.2007.11.001

Belincanta, J., Alchorne, J.A., and Teixeira da Silva, M., The Brazilian experience with ethanol fuel: aspects of production, use, quality and distribution logistics. Brazilian Journal of Chemical Engineering, 33, 1091-1102 (2016). https://doi. org/10.1590/0104-6632.20160334s20150088

Ben-Ameur, W., Computing the initial temperature of simulated annealing. Computational Optimization and Applications, 29, 369-385 (2004). https://doi. org/10.1023/B:COAP.0000044187.23143.bd

Cao, Y., Li, M., Wang, Y., Zhao, T., Li, X., Zhu, Z., and Wang, Y., Effect of feed temperature on economics and controllability of pressure-swing distillation for separating binary azeotrope. Chemical Engineering and Processing: Process Intensification, 110, 160-171 (2016). https://doi. org/10.1016/j.cep.2016.10.011

Cardoso, M.F., Salcedo, R.L., De Azevedo, S.F., and Barbosa, D., Optimization of reactive distillation processes with simulated annealing. Chemical Engineering Science, 55, 5059-5078 (2000). https://doi.org/10.1016/S0009-2509(00)00119-6

Chaudhuri, P.D., and Diwekar, U.M., Synthesis under uncertainty with simulators. Computers \& Chemical Engineering, 21, 733-738 (1997). https:// doi.org/10.1016/S0098-1354(96)00306-7

Chaudhuri, P.D., and Diwekar, U.M., Process synthesis under uncertainty: A penalty function approach. AIChE Journal, 42, 742-752 (1996). https://doi. org/10.1002/aic.690420314

Chaudhuri, P.D., Diwekar, U.M., and Logsdon, J.S., An automated approach for the optimal design of heat exchangers. Industrial \& Engineering Chemistry Research, 36, 3685-3693 (1997). https://doi. org/10.1021/ie970010h

Cheng, J.K., Lee, H.Y., Huang, H.P., and Yu, C.C., Optimal steady-state design of reactive distillation processes using simulated annealing. Journal of the Taiwan Institute of Chemical Engineers, 40, 188-196 (2009). https://doi.org/10.1016/j. jtice.2008.10.003
Claumann, C.A., Peruzzo, T., Felice, V. De, Marangoni, C., and Machado, R.A.F., Modeling and process optimization: an approach using aspen plus and matlab in the energy integration study of distillation columns, in: VIII Congreso Argentino de Ingeniería Química Y 3 JASP, Buenos Aires (2015).

Dolan, W.B., Cummings, P.T., and Le Van, M.D., Process Optimization via Simulated Annealing: Application to Network Design. American Institution of Chemical Engineers, 35, 725-736 (1989). https://doi.org/10.1002/aic.690350504

Dolan, W.B., Cummings, P.T., and Le Van, M.D., Algorithmic efficiency of simulated annealing for heat exchanger network design. Computers \& Chemical Engineering, 14(10), 1039-1050 (1990).

Douglas, J., Conceptual Design of Chemical Processes. McGraw-Hill Book Company, Singapore (1988).

Fulgueras, A.M., Poudel, J., Kim, D.S., and Cho, J., Optimization study of pressure-swing distillation for the separation process of a maximum-boiling azeotropic system of water-ethylenediamine. Korean Journal of Chemical Engineering, 33, 46-56 (2016). https://doi.org/10.1007/s11814-015-0100-4

García-Herreros, P., Gómez, J.M., Gil, I.D., and Rodríguez, G., Optimization of the design and operation of an extractive distillation system for the production of fuel grade ethanol using glycerol as entrainer. Industrial and Engineering Chemistry Research, 50, 3977-3985 (2011). https://doi. org/10.1021/ie101845j

Gutiérrez-Antonio, C., Ojeda-Gasca, A., BonillaPetriciolet, A., Segovia-Hernández, J.G., and Briones-Ramírez, A., Effect of using adjusted parameters, local and global optimums, for phase equilibrium prediction on the synthesis of azeotropic distillation Columns. Industrial and Engineering Chemistry Research, 53, 1489-1502 (2014). https://doi.org/10.1021/ie4019885

Hanke, M., and Li, P., Simulated annealing for the optimization of batch distillation processes. Computers and Chemical Engineering, 24, 1-8 (2000). https:// doi.org/10.1016/S0098-1354(00)00317-3

Hosgor, E., Kucuk, T., Oksal, I.N., and Kaymak, D.B., Design and control of distillation processes for methanol - chloroform separation. Computers and Chemical Engineering, 67, 166-177 (2014). https:// doi.org/10.1016/j.compchemeng.2014.03.026

Iqbal, A., and Ahmad, S.A., Pressure swing distillation of azeotropic mixture - A simulation study. Perspectives in Science, 8, 4-6 (2016). https://doi. org/10.1016/j.pisc.2016.01.001

Kiran, B., and Jana, A.K., A hybrid heat integration scheme for bioethanol separation through pressureswing distillation route. Separation and Purification Technology, 142, 307-315 (2015). https://doi. org/10.1016/j.seppur.2015.01.003 
Kirkpatrick, S., Gelatt, C.D., and Vecch, M.P., Optimization by Simulated Annealing. Science, 220, 671-680 (1983). https://doi.org/10.1126/ science.220.4598.671

Kiss, A.A., Distillation technology - still young and full of breakthrough opportunities. Journal of Chemical Technology \& Biotechnology, 89, 479498 (2013). https://doi.org/10.1002/jctb.4262

Kiss, A.A., Landaeta, S.J.F., and Ferreira, C.A.I., Towards energy efficient distillation technologies Making therightchoice. Energy, 47, 531-542(2012). https://doi.org/10.1016/j.energy.2012.09.038

Kiss, A.A., and Suszwalak, D.J.P.C., Enhanced bioethanol dehydration by extractive and azeotropic distillation in dividing-wall columns. Separation and Purification Technology, 86, 70-78 (2012). https://doi.org/10.1016/j.seppur.2011.10.022

Kumar, S., Singh, N., and Prasad, R., Anhydrous ethanol: A renewable source of energy. Renewable and Sustainable Energy Reviews, 14, 1830-1844 (2010). https://doi.org/10.1016/j.rser.2010.03.015

Kunnakorn, D., Rirksomboon, T., Siemanond, K., Aungkavattana, P., Kuanchertchoo, N., Chuntanalerg, P., Hemra, K., Kulprathipanja, S., James, R.B., and Wongkasemjit, S., Technoeconomic comparison of energy usage between azeotropic distillation and hybrid system for water-ethanol separation. Renewable Energy, 51, 310-316 (2013). https://doi.org/10.1016/j. renene.2012.09.055

Li, R., Ye, Q., Suo, X., Dai, X., and Yu, H., HeatIntegrated Pressure-Swing Distillation Process for Separation of a Maximum-Boiling Azeotrope Ethylenediamine/Water. Chemical Engineering Research and Design, 5, 1-15 (2015). https://doi. org/10.1016/j.cherd.2015.10.038

Liang, S., Cao, Y., Liu, X., Li, X., Zhao, Y., Wang, Y., and Wang, Y., Insight into pressure-swing distillation from azeotropic phenomenon to dynamic control. Chemical Engineering Research and Design, 117, 318-335 (2017). https://doi. org/10.1016/j.cherd.2016.10.040

Linke, P., and Kokossis, A., On the robust application of stochastic optimization technology for the synthesis of reaction/separation systems Computers and Chemical Engineering, 27, 733-758 (2003). https://doi.org/10.1016/S0098-1354(02)00253-3

Lladosa, E., Montón, J.B., and Burguet, M., Separation of di-n-propyl ether and n-propyl alcohol by extractive distillation and pressureswing distillation: Computer simulation and economic optimization. Chemical Engineering and Processing: Process Intensification, 50, 1266-1274 (2011). https://doi.org/10.1016/j.cep.2011.07.010

Luo, H., Liang, K., Li, W., Li, Y., Xia, M., and Xu, C., Comparison of pressure-swing distillation and extractive distillation methods for isopropyl alcohol/diisopropyl ether separation. Industrial and Engineering Chemistry Research, 53, 1516715182 (2014). https://doi.org/10.1021/ie502735g

Luyben, W.L., Methanol/Trimethoxysilane Azeotrope Separation Using Pressure- Swing Distillation. Industrial and Engineering Chemistry Research, 53, 5590-5597 (2014). https://doi.org/10.1021/ie500043c

Luyben, W.L., Comparison of extractive distillation and pressure-swing distillation for acetone/ chloroform separation. Computers and Chemical Engineering, 50, 1-7 (2013). https://doi. org/10.1016/j.compchemeng.2012.10.014

Luyben, W.L., Pressure-swing distillation for minimum- and maximum-boiling homogeneous azeotropes. Industrial and Engineering Chemistry Research, 51, 10881-10886 (2012). https://doi. org/10.1021/ie3002414

Luyben, W.L., Control of the Heterogeneous Azeotropic n-Butanol/Water Distillation System. Energy \& Fuels, 22, 4249-4258 (2008a). https:// doi.org/10.1021/ef8004064

Luyben, W.L., Design and control of a fully heatintegrated pressure-swing azeotropic distillation system. Industrial and Engineering Chemistry Research, 47, 2681-2685 (2008b). https://doi. org/10.1021/ie071366o

Luyben, W.L., Distillation Economic Optimization, in: Distillation Design and Control Using Aspen ${ }^{\mathrm{TM}}$ Simulation. Wiley-Blackwell, pp. 85-97, chapter 4 (2006a). https://doi.org/10.1002/0471785253.ch4

Luyben, W.L., Evaluation of criteria for selecting temperature control trays in distillation columns. Journal of Process Control, 16, 115-134 (2006b). https://doi.org/10.1016/j.jprocont.2005.05.004

Malhotra, R.K., and Das, L.M., Biofuels as blending components for motor gasoline and diesel fuels. Journal of Scientific and Industrial Research, 62, 90-96 (2003). https://doi.org/10.4271/2003-260011

MathWorks, Global Optimization Toolbox: User's Guide (r2016b). URL http://www.mathworks.com/ help/pdf_doc/gads/gads_tb.pdf (2016)

Metropolis, N., Rosenbluth, A.W., Rosenbluth, M.N., Teller, A.H., and Teller, E., Equation of state calculations by fast computing machines. Journal of Chemical Physics, 21, 1087-1092 (1953). https://doi.org/10.1063/1.1699114

Mulia-Soto, J.F., and Flores-Tlacuahuac, A., Modeling, simulation and control of an internally heat integrated pressure-swing distillation process for bioethanol separation. Computers and Chemical Engineering, 35, 1532-1546 (2011). https://doi. org/10.1016/j.compchemeng.2011.03.011

Muñoz, R., Montón, J.B., Burguet, M.C., and de la Torre, J., Separation of isobutyl alcohol and isobutyl 
acetate by extractive distillation and pressureswing distillation: Simulation and optimization. Separation and Purification Technology, 50, 175-183 (2006). https://doi.org/10.1016/j. seppur.2005.11.022

Nourani, Y., and Andresen, B., A comparison of simulated annealing cooling strategies. Journal of Physics A: Mathematical and General, 31, 8373-8385 (1999). https://doi.org/10.1088/03054470/31/41/011

Pla-Franco, J., Lladosa, E., Loras, S., and Montón, J.B., Thermodynamic Analysis and Process Simulation of Ethanol Dehydration via Heterogeneous Azeotropic Distillation. Industrial and Engineering Chemistry Research, 53, 6084-6093 (2014). https://doi.org/10.1021/ie403988c

Quijada-Maldonado, E., Meindersma, G.W., and de Haan, A.B., Ionic liquid effects on mass transfer efficiency in extractive distillation of water-ethanol mixtures. Computers and Chemical Engineering, 71, 210-219 (2014). https://doi.org/10.1016/j. compchemeng.2014.08.002

Rangaiah, G.P., Stochastic Global Optimization:Techniques and Applications in Chemical Engineering. World Scientific, Singapore (2010). https://doi.org/10.1142/7669

Seader, J.D., and Henley, E.J., Separation process principles. Wiley, Hoboken (1998).

Šibalija, T. V., and Majstorović, V.D., Advanced Multiresponse Process Optimisation: An Intelligent and Integrated Approach. Springer International
Publishing, Switzerland (2016). https://doi. org/10.1007/978-3-319-19255-0

Tsuyumoto, M., Teramoto, A., and Meares, P., Dehydration of ethanol on a pilot-plant scale, using a new type of hollow-fiber membrane. Journal of Membrane Science, 133, 83-94 (1997). https://doi. org/10.1016/S0376-7388(97)00090-2

Wang, Y., Bu, G., Wang, Y., Zhao, T., Zhang, Z., and Zhu, Z., Application of a simulated annealing algorithm to design and optimize a pressure-swing distillation process. Computers and Chemical Engineering, 95, 97-107 (2016). https://doi. org/10.1016/j.compchemeng.2016.09.014

Wang, Y., Cui, P., and Zhang, Z., Heat-Integrated Pressure-Swing-Distillation Process for Separation of Tetrahydrofuran/Methanol with Different Feed Compositions. Industrial and Engineering Chemistry Research, 53, 7186-7194 (2014). https://doi.org/10.1021/ie500235f

Zhu, Z., Wang, L., Ma, Y., Wang, W., and Wang, Y., Separating an azeotropic mixture of toluene and ethanol via heat integration pressure swing distillation. Computers and Chemical Engineering, 76, 137-149 (2015). https://doi.org/10.1016/j. compchemeng.2015.02.016

Zhu, Z., Xu, D., Liu, X., Zhang, Z., and Wang, Y., Separation of acetonitrile/methanol/benzene ternary azeotrope via triple column pressureswing distillation. Separation and Purification Technology, 169, 66-77 (2016). https://doi. org/10.1016/j.seppur.2016.06.009 
